Article

\title{
Ni-Mo nitride catalysts: Synthesis and application in the ammoxidation of propane
}

\author{
Xiaoqiang Fan ${ }^{a, \dagger}$, Huimin Zhang b,†, Jianmei Li a , Zhen Zhao ${ }^{\text {a,* }}$, Chunming Xu a, Jian Liu a,\#, \\ Aijun Duan a, Guiyuan Jiang a, Yuechang Wei ${ }^{\text {a }}$ \\ a State Key Laboratory of Heavy Oil Processing, China University of Petroleum, Beijing 102249, China \\ b Department of CTL and Chemicals, Shenhua Group Corporation Ltd, Beijing 100011, China
}

\section{A R T I C L E I N F O}

\section{Article history:}

Received 3 November 2013

Accepted 27 December 2013

Published 20 March 2014

\section{Keywords:}

Nickle-molybdenum nitride

Propane ammoxidation

Acrylonitrile

Preparation method

Nitrogen species

\begin{abstract}
A B S T R A C T
Five different methods were used to prepare the Ni-Mo oxide precursors including sol-gel, rotary evaporation-microwave drying, co-precipitation, impregnation, and mechanical mixing. Ni-Mo nitride catalysts have been synthesized by temperature-programmed nitration of the oxide precursors in a flow of $\mathrm{H}_{2}$ and $\mathrm{N}_{2}$. The structure and physico-chemical properties of the Ni-Mo oxide precursors and their corresponding nitride catalysts were determined by X-ray diffraction, total nitrogen content analysis, X-ray photoelectron spectroscopy and $\mathrm{H}_{2}$ temperature-programmed reduction, and their catalytic performance for propane ammoxidation was also tested. The catalytic activity and selectivity towards the formation of acrylonitrile over the Ni-Mo nitride catalysts are strongly dependent on the preparation methods for the oxide precursors. The $\mathrm{N}$ species in the Ni-Mo nitrides and their mobility and reactivity affect the selectivity for acrylonitrile. The Ni-Mo nitride prepared by co-precipitation, with the largest amount and more reactive $\mathrm{N}$ species, exhibited the highest catalytic activity and selectivity for acrylonitrile.
\end{abstract}

(c) 2014, Dalian Institute of Chemical Physics, Chinese Academy of Sciences. Published by Elsevier B.V. All rights reserved.

\section{Introduction}

Transition metal nitrides have drawn considerable interest in recent years for a number of catalytic reactions owing to their special properties, which are similar to those of group VIII metals [1]. Among them, Mo-based bimetallic nitrides have attracted the most extensive attention in catalytic reactions including ammonia synthesis [2], ammonia decomposition $[3,4]$, hydrodesulfurization [5], and hydrodeoxygenation [6]. Recently, interest in metal nitrides has revealed their potential to act as reservoirs and transfer agents of active nitrogen spe- cies [7]. Hargreaves group [8] has found that the lattice $\mathrm{N}$ species of $\mathrm{Co}_{3} \mathrm{Mo}_{3} \mathrm{~N}$ are exchangeable, and can transform into $\mathrm{Co}_{6} \mathrm{Mo}_{6} \mathrm{~N}$ under $\mathrm{H}_{2} / \mathrm{Ar}$. The lattice $\mathrm{N}$ can supply $\mathrm{N}$ species for reactions in the presence of $\mathrm{H}_{2}$. By analogy with the Mars-van Krevelen mechanism for the involvement of lattice 0 in oxidation reactions from oxide catalysts, highly mobile and exchangeable lattice $\mathrm{N}$ species in nitrides may also undergo the Mars-van Krevelen mechanism for reactions that involve nitrogen.

Acrylonitrile (ACN) is widely used to make acrylic fibers, acrylonitrile-butadiene-styrene, acryl and polyacrylamides, and

†These authors contributed equally to this work.

* Corresponding author. Tel: +86-10-89731586; Fax: +86-10-69724728; E-mail: zhenzhao@cup.edu.cn

\# Corresponding author. Tel: +86-10-89732326; Fax: +86-10-69724728; E-mail: liujian@cup.edu.cn

This work was supported by the National Natural Science Foundation of China (21073235, 21173270, 21177160), the National High Technology Research and Development Program of China (863 Program, 2013AA065302F), and China University of Petroleum Fund (LLYJ-2011-39 and KYJJ2012-06-31). 
elastomers. Currently, the development of highly active and selective catalysts for ammoxidation is important $[9,10]$ and the one-step ammoxidation of propane to ACN has drawn considerable interest in the field of heterogeneous catalysis. Various catalyst systems for propane ammoxidation have been studied, including vanadium phosphorous oxide catalysts [11], antimonite catalysts [12], molybdenum oxide catalysts $[13,14]$, and others [15]. Ueda group [16] has pioneered microporous Mo-V-O based catalysts using heteropoly compounds, which have specific catalytic multi-functions for the selective oxidation and ammoxidation of propane. However, there are very few reports on the ammoxidation of propane over nitride catalysts. In our previous work, Ni-Mo bimetallic nitride catalysts have been tested for the ammoxidation of propane to ACN [17], but their physico-chemical properties needed further study. Most importantly, the reaction mechanism, especially the effect of $\mathrm{N}$ species in the reaction was not clear and needed to be investigated.

The pathway of propane ammoxidation is complicated, and the $\mathrm{N}$-insertion step is crucial. The mechanism over different catalysts is known to be different $[18,19]$. Recently, Olea et al. [20] have proposed the occurrence of a double Mars-van Krevelen mechanism involving both lattice $\mathrm{O}$ and $\mathrm{N}$ during the ammoxidation of propane over VAlON catalysts. For the Ni-Mo nitride catalysts, it is a problem worthy of study to understand if lattice $\mathrm{N}$ is involved in this reaction. It is also worth studying the mobility and reactivity of $\mathrm{N}$ species (both lattice $\mathrm{N}$ and surface $\mathrm{N}$ ) on the Ni-Mo nitride catalysts in the presence of both $\mathrm{O}_{2}$ and $\mathrm{NH}_{3}$.

Moreover, the structure and chemical properties of a nitride have been reported to depend on the synthetic method. The preparation of bimetallic molybdenum nitride has been accomplished by several methods, including reaction of molybdenum nitride and metal [21], ammonolysis of a complex mixed-metal chloride precursor [22], and thermal decomposition of a chemically homogeneous molecular precursor [23]. Most bimetallic molybdenum nitrides have been synthesized by the ammonolysis of precursor oxides [24]. In this method, the structure and chemical properties of nitrides depend on the structure of the precursor oxides, and the conditions employed in oxide nitridation process. The nitridation of different oxide precursors can yield different phases. However, there are few reports on the synthesis of bimetallic nitrides and the effect of precursor-preparation methods on nitride catalysts. Some factors that affect the nitridation have been studied [25] including the $\mathrm{NH}_{3}$ flow-rate, temperature ramp rate, and the final nitridation temperature. Wise et al. [26] improved the procedure by using $\mathrm{N}_{2} / \mathrm{H}_{2}$ to replace $\mathrm{NH}_{3}$ to resolve heat transfer issues. Based on a comparison of $\mathrm{Ni}_{2} \mathrm{Mo}_{3} \mathrm{~N}$ from ammonolysis and $\mathrm{N}_{2} / \mathrm{H}_{2}$ pretreatment of the nickel molybdate, Hargreaves group [8] found that the reactivity of the lattice $\mathrm{N}$ in the $\mathrm{Ni}_{2} \mathrm{Mo}_{3} \mathrm{~N}$ obtained by $\mathrm{N}_{2} / \mathrm{H}_{2}$ pretreatment was more reactive and the nitrides can be used as nitrogen transfer agents. Inspired by their work, we have prepared Ni-Mo bimetallic nitrides by the temperature-programmed reaction of Ni-Mo oxide precursors in $\mathrm{H}_{2} / \mathrm{N}_{2}$ gas mixture, which shows more reactive lattice $\mathrm{N}$ than those from ammonolysis. The aim of the present work is to investigate the effects of the different Ni-Mo oxide precursor preparation methods on physico-chemical properties of Ni-Mo bimetallic nitride catalysts and the role of $\mathrm{N}$ species in the ammoxidation of propane.

\section{Experimental}

\subsection{Catalyst synthesis}

\subsubsection{Preparation of Ni-Mo oxide precursor}

Several preparation methods of precursor oxides were used in this work and the $\mathrm{Mo} / \mathrm{Ni}$ atomic ratio for all preparation methods was 1 .

Co-precipitation (CP). Nickel nitrate and ammonium heptamolybdate were separately dissolved in distilled water and heated to $323 \mathrm{~K}$. The nickel nitrate solution was added slowly to the ammonium heptamolybdate solution. The $\mathrm{pH}$ value was controlled to remain in the range of 4.5 to 5.5 by addition of ammonium hydroxide or nitric acid. The obtained precipitate was filtered, washed, and dried at $383 \mathrm{~K}$ for $12 \mathrm{~h}$. The resulting solid was then calcined at $773 \mathrm{~K}$ for $4 \mathrm{~h}$.

Sol-gel (SG). Citric acid was added to a solution of nickel nitrate $(0.4 \mathrm{~mol} / \mathrm{L})$. Then, a solution of ammonium heptamolybdate was added very slowly to the solution of nickel nitrate to avoid precipitation. The solution was evaporated until first a gel formed and finally, a solid. This solid was calcined at $773 \mathrm{~K}$ for $4 \mathrm{~h}$.

Rotary evaporation-microwave dry (RM). A solution of ammonium heptamolybdate was added into a solution of nickel nitrate $(0.4 \mathrm{~mol} / \mathrm{L})$ at $323 \mathrm{~K}$. The $\mathrm{pH}$ of the solution adjusted to the range of 1.0 to 2.0 by the addition of nitric acid. The solution was then evaporated to dryness on a rotary evaporator. The obtained sample was dried in a microwave oven for $30 \mathrm{~min}$ and calcined at $773 \mathrm{~K}$ for $4 \mathrm{~h}$.

Impregnation (IMP). $\mathrm{MoO}_{3}$ was soaked in a solution of nickel nitrate. After stirring for $1 \mathrm{~h}$, the sample was dried at $383 \mathrm{~K}$ for $12 \mathrm{~h}$, then calcined at $773 \mathrm{~K}$ for $4 \mathrm{~h}$.

Mechanical mixture (MM). Powders of ammonium heptamolybdate and nickel nitrate were mixed and ground in a mortar for $1 \mathrm{~h}$. Then the mixture was calcined at $773 \mathrm{~K}$ for $4 \mathrm{~h}$.

\subsubsection{Synthesis of the Ni-Mo nitride catalyst}

Ni-Mo nitrides were synthesized by temperature-programmed nitration of their corresponding metal oxide precursors in a mixture of $\mathrm{H}_{2} / \mathrm{N}_{2}$ [26]. A typical synthesis was as follows: a total of $4 \mathrm{~g}$ of the oxide precursor was placed in the tubular quartz reactor ( $\varphi 18 \mathrm{~mm}$ ). The WHSV of $80 \% \mathrm{H}_{2} / \mathrm{N}_{2}$ mixture was at a $18000 \mathrm{ml} /(\mathrm{g} \cdot \mathrm{h})$. The temperature was increased in three steps: first, rapidly from room temperature to $573 \mathrm{~K}(10 \mathrm{~K} / \mathrm{min})$, then more slowly from 573 to $673 \mathrm{~K}(0.5$ $\mathrm{K} / \mathrm{min})$, and finally from 673 to $973 \mathrm{~K}(1.7 \mathrm{~K} / \mathrm{min})$. The temperature was held at $973 \mathrm{~K}$ for $4 \mathrm{~h}$. The system was then cooled to room temperature in flowing $\mathrm{N}_{2}$ and passivated under $1 \%$ $\mathrm{O}_{2} / \mathrm{N}_{2}$ for $12 \mathrm{~h}$ to avoid bulk oxidation.

\subsection{Characterization of materials}


The specific surface areas of the Ni-Mo nitride catalysts were measured from the linear parts of a BET plot of the $\mathrm{N}_{2}$ isotherms on a Micromeritics ASPA-2010 analyzer.

The total nitrogen content $\left(\mathrm{N}_{\mathrm{T}}\right)$ analysis, including bulk and surface nitrogen, was determined according to the method described by Guyader et al. [27].

$\mathrm{X}$-ray diffraction (XRD) measurements were performed on a diffractometer (Shimadzu XRD-6000) with $\mathrm{Cu} K_{\alpha}$ radiation over a $2 \theta$ range of $20^{\circ}$ to $80^{\circ}$, with a scan speed of $4^{\circ} / \mathrm{min}$.

$\mathrm{H}_{2}$ temperature-programmed reduction $\left(\mathrm{H}_{2}\right.$-TPR) experiments were carried out in a conventional flow apparatus. A nitride sample $(0.2 \mathrm{~g})$ was pretreated under He by calcination at $393 \mathrm{~K}$ for $1 \mathrm{~h}$ and subsequently cooled to room temperature. A $5 \% \mathrm{H}_{2} / \mathrm{Ar}$ gas mixture $(50 \mathrm{ml} / \mathrm{min}$ ) was passed through the sample while the temperature was increased at a rate of 10 $\mathrm{K} / \mathrm{min}$ to $1223 \mathrm{~K}$. The effluent gases were sampled with a Quantachrome Autosorb-1 mass spectrometer chamber through a variable leak valve. The mass signals of these effluent gases were recorded.

X-ray photoelectron spectroscopy (XPS) was recorded on a Perkin-Elmer PHI Quantera SEX spectrometer using a Mg $K_{\alpha}$ $\mathrm{X}$-ray source. The binding energy (BE) was calibrated using the $\mathrm{C} 1 s$ peak of contaminant carbon $(\mathrm{BE}=284.6 \mathrm{eV})$ as an internal standard.

\subsection{Activity measurements}

The catalytic activity tests were performed in a fixed-bed reactor at atmospheric pressure. The catalyst (1 g, 20-40 mesh) was used to test its activity for propane ammoxidation. The feed gases consisted of a mixture of $\mathrm{C}_{3} \mathrm{H}_{8}: \mathrm{NH}_{3}: \mathrm{O}_{2}: \mathrm{He}$ with a molar ratio of 1:7.5:7.5:34. The total flow rate was $14.5 \mathrm{ml} / \mathrm{min}$. The axial temperature profile was monitored by a thermocouple, which was inserted into the catalyst bed. Experiments were carried out over the temperature range of 693-793 K. The reactor outlet was kept at $443 \mathrm{~K}$. The activity results were measured after $12 \mathrm{~h}$ on stream. Feed and products were analyzed on-line by a gas chromatograph (SP-2100), equipped with a FID detector. A Porapak $\mathrm{Q}$ column was used for the separation of $\mathrm{CO}, \mathrm{CO}_{2}, \mathrm{C}_{2} \mathrm{H}_{4}, \mathrm{C}_{3} \mathrm{H}_{6}, \mathrm{C}_{3} \mathrm{H}_{8}, \mathrm{CH}_{3} \mathrm{CN}, \mathrm{CH}_{2}=\mathrm{CHCHO}$, and ACN. The concentrations of the products were determined with a FID detector with a methane converter operating at $653 \mathrm{~K}$ with a $\mathrm{Ni}$ catalyst.

\section{Results and discussion}

\subsection{Structural characterization of the nitride catalysts}

Figure 1 shows the XRD patterns of the Ni-Mo nitrides catalysts. The peaks at $2 \theta=40.8^{\circ}, 43.0^{\circ}$, and $45.3^{\circ}$ are detected in all samples, indicating the formation of $\mathrm{Ni}_{2} \mathrm{Mo}_{3} \mathrm{~N}$ [28]. The IMP, $\mathrm{MM}$, and $\mathrm{CP}$ method catalysts show peaks at $2 \theta=37.4^{\circ}, 44.0^{\circ}$, and $63.0^{\circ}$, which are assigned to the (111), (200), and (220) reflections of $\gamma-\mathrm{Mo}_{2} \mathrm{~N}$. In our previous work, the effects of the preparation methods on the phase structure of Ni-Mo oxides were studied [29]. The same $\mathrm{MoO}_{3}$ phases were detected in the IMP, MM, and CP method samples. The $\gamma-\mathrm{Mo}_{2} \mathrm{~N}$ phases in these

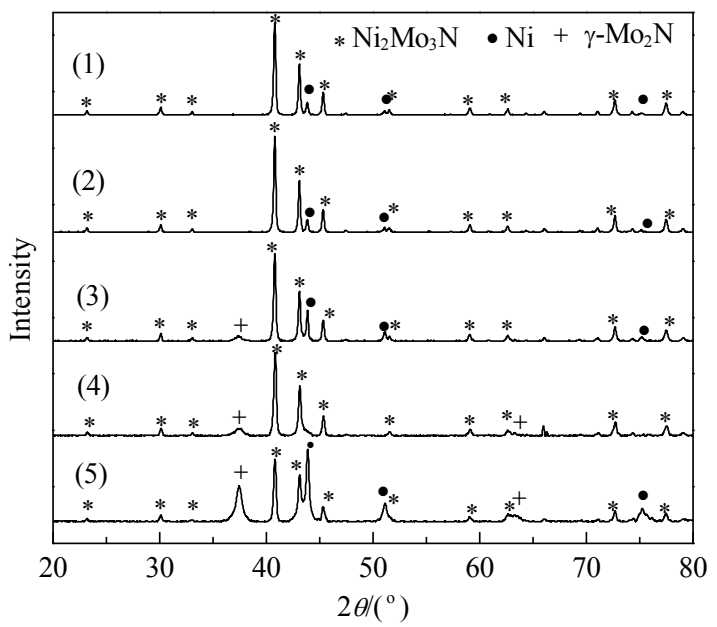

Fig. 1. XRD patterns of the Ni-Mo nitride catalysts with the oxide precursor prepared by different methods. (1) SG; (2) RM; (3) IMP; (4) CP; (5) MM.

three nitride catalysts have been formed by nitridation of the $\mathrm{MoO}_{3}$ from the oxide precursors. In addition, all the catalysts show a diffraction pattern of $\mathrm{Ni}$, which confirms a Ni:Mo ratio of one except for the CP method. The absence of $\mathrm{Ni}$ in Ni-Mo nitride-CP may be caused by loss of the Ni precursor during filtering and it is further confirmed by the presence of $\mathrm{NiMoO}_{4}$ and $\mathrm{MoO}_{3}$ in the oxide precursor [29].

The specific surface areas and the total $\mathrm{N}$ contents of Ni-Mo nitride catalysts are listed in Table 1 . The $\gamma-\mathrm{Mo}_{2} \mathrm{~N}$ sample shows the largest surface area and the surface areas of the nitrides containing $\mathrm{Ni}_{2} \mathrm{Mo}_{3} \mathrm{~N}$ and $\gamma-\mathrm{Mo}_{2} \mathrm{~N}$ (CP, IMP, and MM) are larger than that of pure $\mathrm{Ni}_{2} \mathrm{Mo}_{3} \mathrm{~N}$ ( $\mathrm{SG}$ and RM). The BET surface area of Ni-Mo nitride-CP $\left(47.8 \mathrm{~m}^{2} / \mathrm{g}\right)$ is the largest among the $\mathrm{Ni}-\mathrm{Mo}$ nitrides, while those of Ni-Mo nitride-SG $\left(4.6 \mathrm{~m}^{2} / \mathrm{g}\right)$ and $\mathrm{Ni}-\mathrm{Mo}$ nitride-RM $\left(5.7 \mathrm{~m}^{2} / \mathrm{g}\right)$ are much lower. Moreover, the total $\mathrm{N}$ content of Ni-Mo nitride-CP is also the highest among all the $\mathrm{Ni}-\mathrm{Mo}$ nitride catalysts.

\subsection{Physico-chemical properties of Ni-Mo nitride catalysts}

Because Ni-Mo nitride is a pyrophoric compound, a passivation step is necessary for the nitride to avoid bulk oxidation on contact with air. After nitrides are exposed to passivation gases under mild conditions, some oxygen can diffuse into the subsurface layers of the nitride or a thin passivation layer can appear, which does not form a distinct oxide phase. The $\mathrm{H}_{2}$-TPR was carried out using the passivated $\mathrm{Ni}-\mathrm{Mo}$ nitride catalysts and the results are shown in Fig. 2 . The preparation method of

Table 1

BET surface areas and total N content of nitride catalysts.

\begin{tabular}{lcc}
\hline Sample & $A_{\text {BET }}\left(\mathrm{m}^{2} / \mathrm{g}\right)$ & Total N content $(\mathrm{wt} \%)$ \\
\hline Ni-Mo nitride-SG & 4.6 & 2.8 \\
Ni-Mo nitride-RM & 5.7 & 4.0 \\
Ni-Mo nitride-IMP & 13.9 & 3.0 \\
Ni-Mo nitride-MM & 14.2 & 3.3 \\
Ni-Mo nitride-CP & 47.8 & 4.4 \\
$\gamma$-Mo $2 \mathrm{~N}$ & 59.8 & 4.5 \\
\hline
\end{tabular}



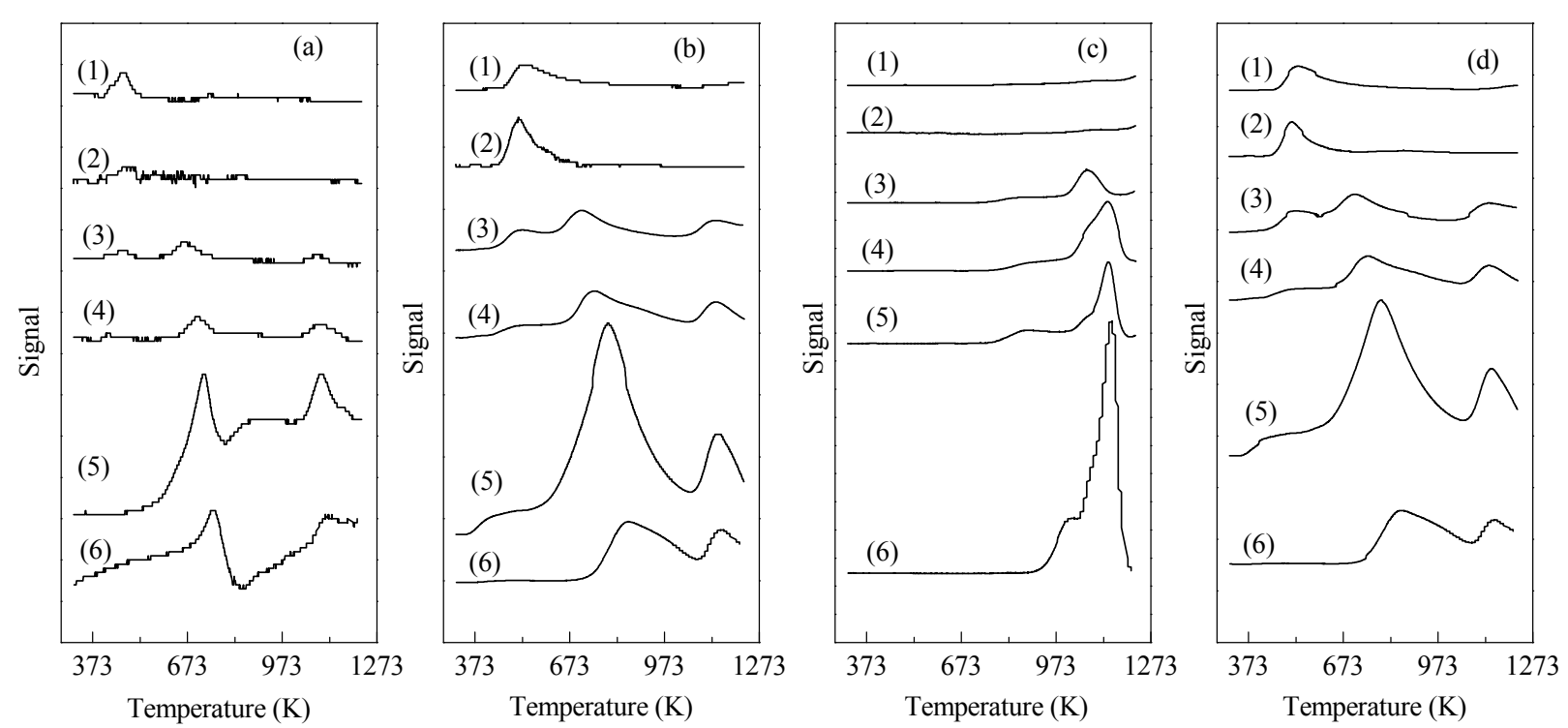

Fig. 2. $\mathrm{H}_{2}$-TPR profiles of different Ni-Mo nitrides. (a) $\mathrm{H}_{2}$ consumption; (b) $\mathrm{NH}_{3}$ desorption; (c) $\mathrm{N}_{2}$ desorption; (d) $\mathrm{H}_{2} \mathrm{O}$ desorption. (1) Ni-Mo nitride-SG; (2) Ni-Mo nitride-RM; (3) Ni-Mo nitride-IMP; (4) Ni-Mo nitride-MM; (5) Ni-Mo nitride-CP; (6) $\gamma$-Mo $\mathrm{M}_{2} \mathrm{~N}$.

the oxide precursor clearly influences the redox properties of the Ni-Mo nitride catalysts. The $\mathrm{H}_{2}$ consumption and $\mathrm{H}_{2} \mathrm{O}$ and $\mathrm{NH}_{3}$ desorption are observed in all samples, and the $\mathrm{N}_{2}$ desorption is also observed in the high-temperature region. In $\gamma-\mathrm{Mo}_{2} \mathrm{~N}$, the $\mathrm{H}_{2}$ consumption peaks are evident in two temperature regions: low-temperature region around $756 \mathrm{~K}$ and high-temperature region around $1110 \mathrm{~K}$, which could be associated with hydrogen consumption associated with the removal of the passivation layer and lattice $\mathrm{N}[30]$.

From Fig. 2 (a), it can be seen that the addition of Ni decreases the reduction temperature of the passivation layer of $\mathrm{Ni}$-Mo nitride catalysts, which indicates that the redox capacity of the catalysts has been improved by the addition of $\mathrm{Ni}$ [31]. For Ni-Mo nitride-SG and Ni-Mo nitride- $\mathrm{RM}$, the $\mathrm{H}_{2}$ consumption peaks are observed only in the low-temperature region around $470 \mathrm{~K}$, indicating good redox properties, but no $\mathrm{H}_{2}$ consumption peaks are observed in the high-temperature region. For Ni-Mo nitride-IMP and Ni-Mo nitride-MM, the $\mathrm{H}_{2}$ consumption peaks are found in three temperature regions: low-temperature region around $450 \mathrm{~K}$, medium-temperature region around $700 \mathrm{~K}$, and high-temperature region around 1090 K. For Ni-Mo nitride-CP, no $\mathrm{H}_{2}$ consumption peaks are observed in low-temperature region, but still appear in the other two temperature regions. As shown in Fig. 2(c), the thermal stability of Ni-Mo nitride catalysts is different. For $\gamma$-MozN, Ni-Mo nitride-IMP, Ni-Mo nitride-CP, and Ni-Mo nitride-MM, the $\mathrm{N}_{2}$ signal increases slowly in the temperature region of 773-1045 K, but at temperatures greater than 1045 $\mathrm{K}$, the $\mathrm{N}_{2}$ signal quickly rises and exhibits a sharp peak at around $1100 \mathrm{~K}$. Ni-Mo nitride-SG and Ni-Mo nitride-RM have no $\mathrm{N}_{2}$ desorption peaks below $1200 \mathrm{~K}$, indicating that they are more stable than the other samples.

As shown in Fig. 2(b) and (d), $\mathrm{NH}_{3}$ and $\mathrm{H}_{2} \mathrm{O}$ were desorbed at the same temperatures at which $\mathrm{H}_{2}$ was consumed. As far as desorption of $\mathrm{NH}_{3}$ is concerned, it can be found that three $\mathrm{NH}_{3}$ desorption peaks are present. The first is the most likely a weakly adsorbed $\mathrm{NH}_{x}$ species that is desorbed at $470-570 \mathrm{~K}$ [31]. The second is believed to be the result of the reaction between surface $\mathrm{N}$ species and $\mathrm{H}_{2}$. The third, therefore, would originate from $\mathrm{N}$ species within the crystal lattice. As shown in Fig. 2 (b), Ni-Mo nitride-SG and Ni-Mo nitride-RM are so stable that the lattice $\mathrm{N}$ hardly reacts with $\mathrm{H}_{2}$, indicating low lattice nitrogen mobility. On the contrary, for the other three Ni-Mo nitrides, the lattice $\mathrm{N}$ is more reactive, especially in Ni-Mo nitride-CP. The mobility of the $\mathrm{N}$ species can be estimated by comparing the desorption peak areas of $\mathrm{NH}_{3}$ during $\mathrm{H}_{2}$-TPR over the Ni-Mo nitrides prepared by different methods, and these results are listed in Table 2 . These nitrides clearly show different mobility of lattice $\mathrm{N}$. The $\mathrm{H}_{2}$ consumption peak areas indicate the redox properties of the Ni-Mo nitride catalysts. As shown in Tables 2 and 3, Ni-Mo nitride-SG, Ni-Mo nitride-RM, and Ni-Mo nitride-IMP catalysts exhibit strong redox properties in the low-temperature region and good reactivity of surface $\mathrm{N}$ species (peak I), while the Ni-Mo nitride-CP shows good mobility and reactivity of the lattice $\mathrm{N}$ species (peak II and III).

An interesting phenomenon takes place in the $\mathrm{H}_{2}$-TPR process, where oxygen is removed as $\mathrm{H}_{2} \mathrm{O}$ (Fig. 2(d)). These $\mathrm{O}$ species most likely come from the Ni-Mo nitride catalyst passivation layer. There are three desorption peaks of $\mathrm{H}_{2} \mathrm{O}$ in Fig. 2 (d). The first, at low temperature $(\sim 510 \mathrm{~K})$, likely comes from

Table 2

$\mathrm{NH}_{3}$ desorption results for the Ni-Mo nitrides during $\mathrm{H}_{2}$-TPR.

\begin{tabular}{lccccccccc}
\hline \multirow{2}{*}{ Sample } & \multicolumn{3}{c}{ Peak temperature $(\mathrm{K})$} & & \multicolumn{4}{c}{ Peak area $\left(10^{-9}\right)$} \\
\cline { 2 - 4 } \cline { 7 - 9 } & I & II & III & & I & II & III & Total \\
\hline$\gamma$-Mo2N & 462 & 872 & 1184 & & - & 0.3 & 0.2 & 0.5 \\
Ni-Mo nitride-SG & 526 & - & 1222 & & 0.1 & - & - & 0.1 \\
Ni-Mo nitride-RM & 507 & 862 & - & & 0.1 & - & - & 0.1 \\
Ni-Mo nitride-IMP & 522 & 707 & 1130 & & 0.1 & 0.2 & 0.1 & 0.4 \\
Ni-Mo nitride-MM & 507 & 745 & 1135 & & 0.1 & 0.3 & 0.2 & 0.6 \\
Ni-Mo nitride-CP & 449 & 789 & 1140 & & 0.1 & 1.1 & 0.5 & 1.7 \\
\hline
\end{tabular}


Table 3

$\mathrm{H}_{2}$ consumption results for the Ni-Mo nitrides during $\mathrm{H}_{2}$-TPR.

\begin{tabular}{|c|c|c|c|c|c|c|c|}
\hline \multirow{2}{*}{ Sample } & \multicolumn{3}{|c|}{ Peak temperature $(\mathrm{K})$} & \multicolumn{4}{|c|}{ Peak area $\left(10^{-10}\right)$} \\
\hline & $\mathrm{I}$ & II & III & I & II & III & Total \\
\hline$\gamma-\mathrm{Mo}_{2} \mathrm{~N}$ & - & 756 & 1139 & - & 2.7 & 2.1 & 4.8 \\
\hline Ni-Mo nitri & 460 & - & - & 0.8 & - & - & 0.8 \\
\hline Ni-Mo nitride-RM & 473 & - & - & 0.4 & - & - & 0.4 \\
\hline Ni-Mo nitride-IMP & 458 & 663 & 1081 & 0.3 & 0.5 & 0.2 & 1.0 \\
\hline Ni-Mo ni & 424 & 702 & 1091 & 0.1 & 0.5 & 0.3 & 0.9 \\
\hline Ni-Mo nitride-CP & - & 721 & 1096 & - & 5.1 & 4.7 & 9.8 \\
\hline
\end{tabular}

Table 4

$\mathrm{H}_{2} \mathrm{O}$ desorption results for the Ni-Mo nitrides during $\mathrm{H}_{2}$-TPR.

\begin{tabular}{|c|c|c|c|c|c|c|c|}
\hline \multirow{2}{*}{ Sample } & \multicolumn{3}{|c|}{ Peak temperature $(\mathrm{K})$} & \multicolumn{4}{|c|}{ Peak area $\left(10^{-9}\right)$} \\
\hline & I & II & III & $I$ & II & III & Total \\
\hline$\gamma-\mathrm{Mo}_{2} \mathrm{~N}$ & - & 872 & 1184 & - & 1.2 & 0.8 & 2.0 \\
\hline Ni-Mo nitride-SG & 526 & - & 1222 & 0.5 & - & 0.1 & 0.6 \\
\hline Ni-Mo 1 & 507 & 862 & - & 0.7 & 0.1 & - & 0.8 \\
\hline Ni-Mo nitride-IMP & 522 & 707 & 1130 & 0.5 & 0.9 & 0.6 & 2.0 \\
\hline Ni-Mo nitride-MM & 507 & 745 & 1135 & 0.3 & 1.2 & 0.8 & 2.3 \\
\hline Ni-Mo nitride-CP & 449 & 789 & 1140 & 0.5 & 4.0 & 1.9 & 6.4 \\
\hline
\end{tabular}

the reduction of chemisorbed surface active 0 species. The second, in the range of 707-872 K, is thought to be a reduction of more strongly chemisorbed active $\mathrm{O}$ in the passivated layer; and the third one is the reduction of 0 species in crystal lattice. Colling et al. [32] reported that oxygen can be incorporated into the lattice of the nitrides during the passivation step. Table 4 shows the amount of $\mathrm{H}_{2} \mathrm{O}$ desorption at different temperatures in the $\mathrm{H}_{2}$-TPR process. The amount of $\mathrm{H}_{2} \mathrm{O}$ desorption from Ni-Mo nitride-CP at $789 \mathrm{~K}$ (Peak II temperature) is the largest, indicating the largest amount of chemisorbed surface active 0 species.

\subsection{Catalytic activity results}

Figure 3 shows the propane conversion at different temperatures over $\gamma-\mathrm{Mo}_{2} \mathrm{~N}$ and various Ni-Mo nitride catalysts. At $693-793 \mathrm{~K}$ propane conversion is very low $(<10 \%)$ over the $\gamma-\mathrm{Mo}_{2} \mathrm{~N}$ catalyst, but it is much higher over the $\mathrm{Ni}-\mathrm{Mo}$ nitride catalysts. The addition of Ni favors the formation of a defect structure in Ni-Mo [33], which in turn tends to form a defective

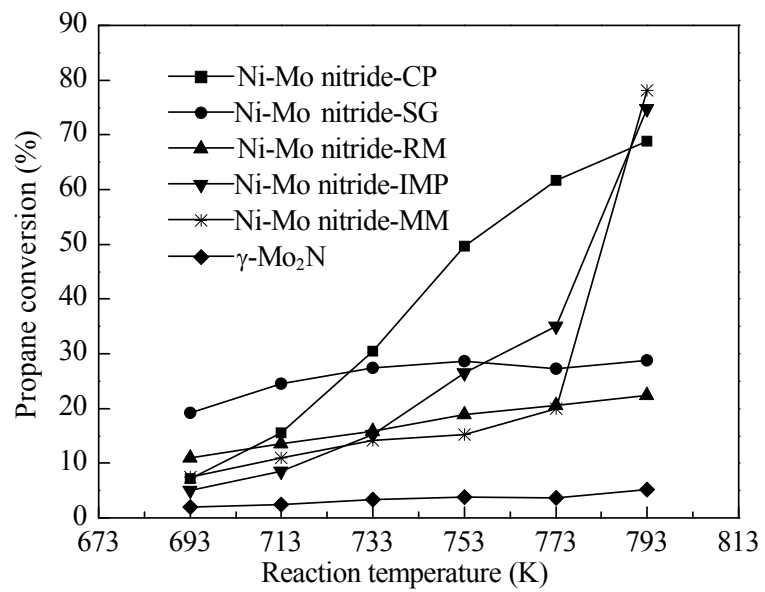

Fig. 3. Propane conversion as a function of the reaction temperature over $\gamma$-Mon $\mathrm{N}$ and Ni-Mo nitride catalysts. structure in the Ni-Mo nitride catalysts synthesized by a topotactic reaction. The defective structure favors oxygen transport by the oxidation of $\mathrm{Ni}^{2+}$ to $\mathrm{Ni}^{3+}$. Therefore, a Ni-Mo bimetallic nitride catalyst is necessary for propane activation. The different methods make great differences in catalytic activity of Ni-Mo nitride catalysts. As far as the Ni-Mo nitride-SG and $\mathrm{Ni}$-Mo nitride-RM catalysts are concerned, the conversion of propane is higher (19.2\% for Ni-Mo nitride-SG and $11.2 \%$ for Ni-Mo nitride-RM at $693 \mathrm{~K}$ ) at 693-713 K, but have no increase in catalytic activity $(\sim 20 \%)$ above $733 \mathrm{~K}$. On the contrary, the Ni-Mo nitride-IMP, Ni-Mo nitride-MM, and Ni-Mo nitride-CP catalysts show low catalytic activity $(<10 \%)$ at $693 \mathrm{~K}$ but much higher catalytic activity (> 65\%) at $793 \mathrm{~K}$. The differences in catalytic activity of these samples are consistent with $\mathrm{H}_{2}$-TPR results, which indicate that the redox properties of Ni-Mo nitride catalysts and the mobility of $\mathrm{O}$ species play an important role in improving the catalytic activity. It can be seen that the passivation step is essential because it offers the active 0 species required at the beginning of the propane ammoxidation process.

Figure 4 displays the selectivity for ACN over the Ni-Mo nitride catalysts at 713,733 , and $753 \mathrm{~K}$. It can be seen that the selectivity for ACN gradually increases as reaction temperatures increased from 713 to $753 \mathrm{~K}$. Comparing the five different samples, the CP sample gives the highest selectivity for ACN (35.4\% at $753 \mathrm{~K})$. The RM and IMP samples are relatively analogous in terms of selectivity for ACN, especially at low reaction temperatures (713 K), but the IMP sample shows higher selectivity for ACN than the RM sample as the reaction temperature increases. The selectivity of SG sample is slightly lower, and that of the MM sample is the lowest $(<10 \%)$.

Considering that the Ni-Mo oxides have shown high catalytic performance for propane dehydrogenation to propene [34], propene may be the intermediate in this ammoxidation of propane. To confirm this hypothesis, the selectivity for different products over the Ni-Mo nitride-CP varied with contact time at $753 \mathrm{~K}$ is shown in Fig. 5. It indicates that the selectivity for propene decreases, while that to $\mathrm{CO}_{x}$ and ACN increase with increasing contact time. This suggests that propene is formed first and subsequently converts to ACN and $\mathrm{CO}_{x}$.

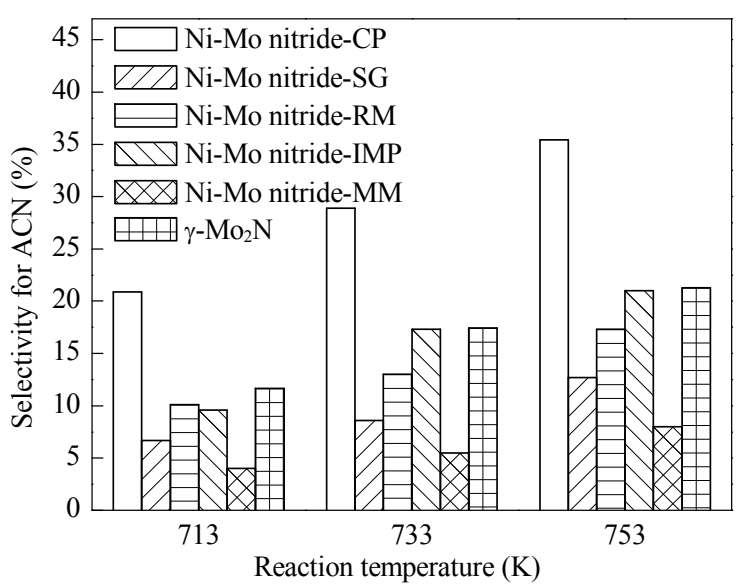

Fig. 4. Selectivity for ACN as a function of reaction temperature over $\gamma-\mathrm{Mo}_{2} \mathrm{~N}$ and different Ni-Mo nitride catalysts. 


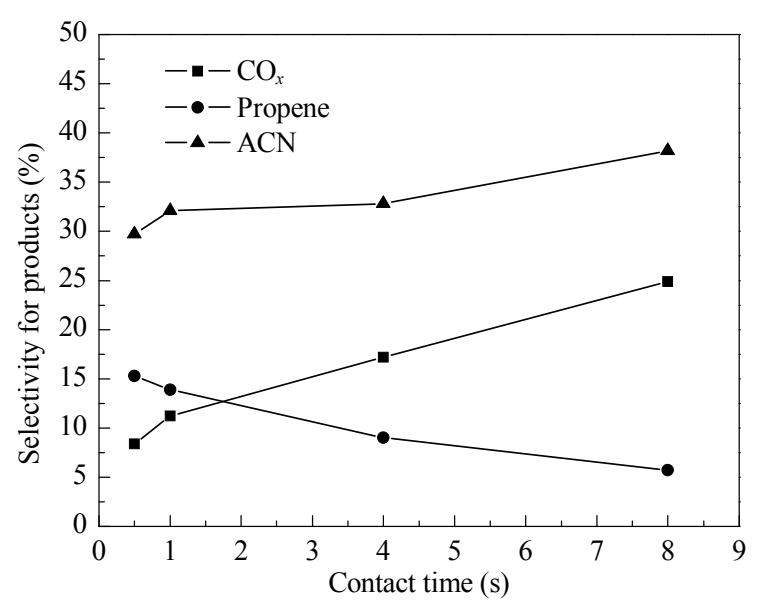

Fig. 5. Selectivity for various products as a function of contact time at $753 \mathrm{~K}$ over the Ni-Mo nitride-CP catalyst.

\subsection{The role of nitrogen species in propane ammoxidation}

The preparation methods affect the phase compositions of the crystallites of $\gamma-\mathrm{Mo}_{2} \mathrm{~N}, \mathrm{Ni}_{2} \mathrm{Mo}_{3} \mathrm{~N}$, and metal Ni (Fig. 1), the specific surface areas (Table 1), the total nitrogen contents (Table 1), the redox properties, and the mobility of $\mathrm{O}$ and $\mathrm{N}$ species (Fig. 2 and Tables 2-4) of the Ni-Mo nitride catalysts. It is thus difficult to determine how much each of these factors control the catalytic properties. However, a general feature of the samples prepared by all these methods is that the propane conversion is higher over Ni-Mo bimetallic nitrides than over $\gamma-\mathrm{Mo}_{2} \mathrm{~N}$.

The specific surface area of the Ni-Mo nitride catalyst also influences the catalytic activity. The Ni-Mo nitride-CP with large specific surface area exhibits the highest catalytic activity, while the Ni-Mo nitride-SG and Ni-Mo nitride-RM, with low surface areas, show poor catalytic performance at high temperature.

Moreover, the crystallite compositions of the Ni-Mo nitrides prepared by different methods also play important roles in the formation of ACN. The Ni-Mo nitride-MM with a lot of metallic $\mathrm{Ni}$ shows the lowest selectivity for ACN, indicating that the existence of metallic $\mathrm{Ni}$ causes adverse effects in the formation of ACN. The coexistence of $\gamma-\mathrm{Mo}_{2} \mathrm{~N}$ and $\mathrm{Ni}_{2} \mathrm{Mo}_{3} \mathrm{~N}$ (Ni-Mo nitride-CP and Ni-Mo nitride-IMP) exhibits higher selectivity for ACN than the Ni-Mo nitrides without $\gamma-\mathrm{Mo}_{2} \mathrm{~N}$. $\mathrm{Mo}_{2} \mathrm{~N}$ has a high capacity for absorbing both inorganic molecules $\left(\mathrm{NH}_{3}, \mathrm{O}_{2}\right)$ and organic molecules [35]. Thus, the nitrides with $\mathrm{Mo}_{2} \mathrm{~N}$ can effectively adsorb the reactant molecules.

Comparing the results in Fig. 3 with Fig. 2, one can find that the propane conversion on the five Ni-Mo nitride catalysts is correlated with the redox properties and the amount of 0 species. As shown in Fig. 4, the preparation methods also markedly affect the selectivity for ACN. The Ni-Mo nitride-CP catalyst exhibits the highest selectivity among the catalysts. From the total $\mathrm{N}$ contents of the Ni-Mo nitrides (Table 1) and $\mathrm{H}_{2}$-TPR results (Fig. 2 and Table 2), it can be seen that the Ni-Mo nitride-CP exhibits a higher $\mathrm{N}$ content and higher mobility of $\mathrm{N}$ species than other samples, which indicates that these proper- ties are closely related to their selectivity. In addition, combining Table 2 and Fig. 4, it shows that the selectivity for ACN decreases with decreasing amounts of the $\mathrm{N}$ species (peak I + peak II), except for Ni-Mo nitride-MM.

To further investigate the effect of $\mathrm{N}$ and $\mathrm{O}$ species on catalytic performance, XPS and XRD characterization of Ni-Mo nitride-CP before and after the reaction were carried out. In the catalyst, the generation of a passivation layer adds 0 species. To examine the surface 0 species in the Ni-Mo nitride catalyst before the propane ammoxidation reaction, the Ni-Mo nitride-CP was studied by XPS, before and after sputtering, and the results are shown in Fig. 6. The $01 s$ spectra before and after sputtering are very similar, which demonstrates that the peak at $530.6 \mathrm{eV}$ can be assigned to lattice 0 species. The peak at $532.5 \mathrm{eV}$ has been assigned to an adsorbed 0 species. This indicates the existence of at least two $\mathrm{O}$ species in the Ni-Mo nitride catalyst and the possibility of Mars-van Krevelen mechanism for the propane ammoxidation reaction over a Ni-Mo nitride catalyst. The result confirms that the surface of the passivated Ni-Mo nitride consists mainly of an oxynitride rather than a nitride. XRD patterns of Ni-Mo nitride-CP before and after the reaction are shown in Fig. 7. It can be seen that after the ammoxidation reaction, the diffraction peaks of $\mathrm{Ni}_{2} \mathrm{Mo}_{3} \mathrm{~N}$ disappear and peaks assigned to $\mathrm{MoO}_{2}$ appear along with some $\mathrm{NiMoO}_{4}$ and $\mathrm{MoO}_{3}$. This indicates the $\mathrm{N}$ species is consumed during the reaction. The total $\mathrm{N}$ content of $\mathrm{Ni}-\mathrm{Mo}$ nitride $\mathrm{CP}$ after the reaction is only $0.03 \%$. The XPS results (Fig. 8) of $\mathrm{N} 1 s$ show the nature of the nitrogen in the sample after propane ammoxidation reaction. The binding energy at 395.5 $\mathrm{eV}$ could be assigned to Mo-O-N bond [36], and the peak at $398.8 \mathrm{eV}$ should be assigned to $\mathrm{NH}_{3}$ adsorbed on the surface [37]. According to these XPS and XRD results, it appears that the lattice $\mathrm{N}$ species is involved in the ammoxidation reaction directly, and takes part in the formation of ACN. At the beginning of the propane ammoxidation procedure, propane is activated by the $\mathrm{O}$ species in the passivation layer of Ni-Mo nitride and propene is formed as an intermediate. The 0 vacancy is

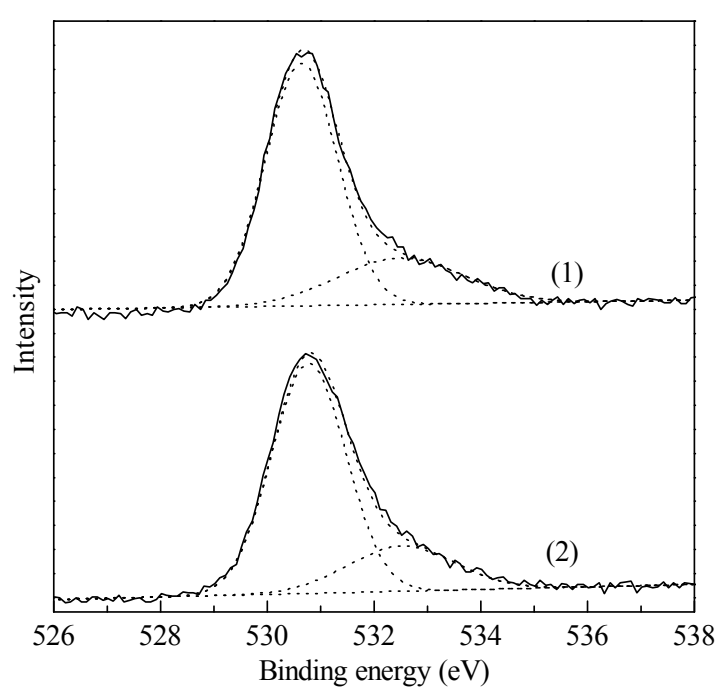

Fig. 6. The XPS spectra of $01 s$ for the Ni-Mo nitride CP before (1) and after (2) sputtering, before the propane ammoxidation reaction. 


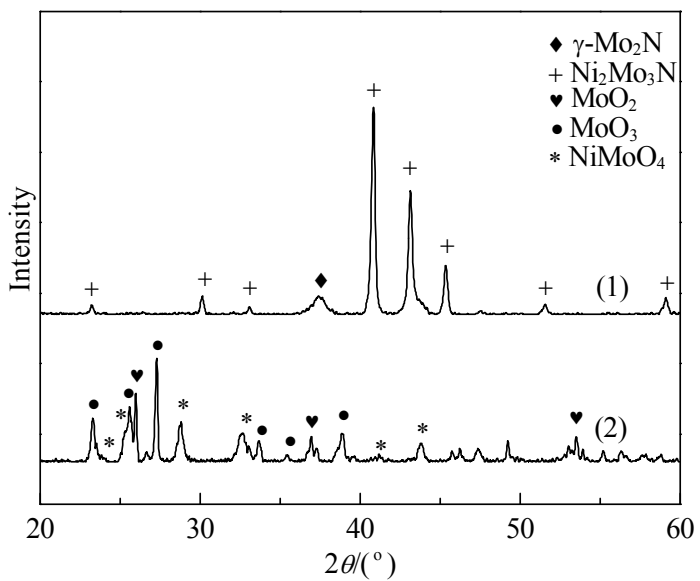

Fig. 7. XRD patterns of Ni-Mo nitride-CP before (1) and after (2) propane ammoxidation reaction.

replenished by $\mathrm{O}_{2}$ from the gas phase. $\mathrm{N}$ species in the $\mathrm{Ni}-\mathrm{Mo}$ nitride surface then participate in the $\mathrm{N}$-insertion step with propene, as seen from the decrease of $\mathrm{N}$ content after the ammoxidation reaction. $\mathrm{N}$ vacancies are formed by the consumption of surface $\mathrm{N}$ species. Subsequently, these vacancies are replenished partly by $\mathrm{N}$ diffusion from the bulk and partly by $\mathrm{O}_{2}$ or $\mathrm{NH}_{3}$ from the gas phase. Oxygen also diffuses to the bulk from the surface to fill the $\mathrm{N}$ vacancies, which is seen in the XRD results after the reaction. By re-nitridation of the sample after the reaction, the Ni-Mo nitride can be regenerated [38]. Gas phase $\mathrm{NH}_{3}$ is used to rebalance the $\mathrm{N}$ species on the catalyst surface for the N-insertion step, as also seen in the XPS result (Fig. 8), there are $\mathrm{N}$ species on the surface after the reaction.

In general, Ni-Mo nitride-CP shows the best catalytic performance. The reasons for this are as follows: (1) Ni-Mo nitride-CP mainly consists of both $\mathrm{Ni}_{2} \mathrm{Mo}_{3} \mathrm{~N}$ and $\mathrm{Mo}_{2} \mathrm{~N}$ phases; (2) it shows the largest amount of active $\mathrm{O}$ species, which favors the activation of the $\mathrm{C}-\mathrm{H}$ in propane; (3) the amount and the mobility of $\mathrm{N}$ species play important roles in the selectivity for ACN. This large amount takes advantage of the $\mathrm{N}$-insertion during the ammoxidation. Therefore, Ni-Mo nitride-CP shows the best catalytic performance.

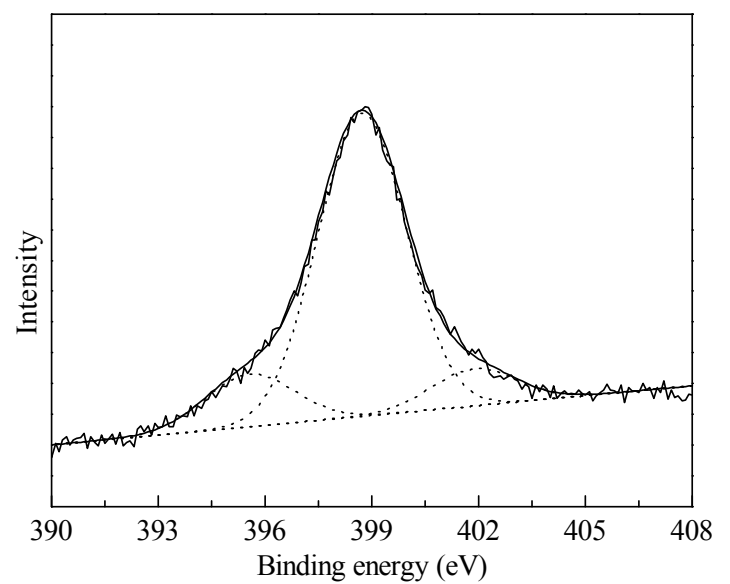

Fig. 8. The $\mathrm{N} 1 s$ XPS spectrum of Ni-Mo nitride-CP after the propane ammoxidation reaction.

\section{Conclusions}

The Ni-Mo oxide precursors were prepared by five different methods and were used to successfully synthesize the corresponding nitrides by temperature-programmed nitration in $\mathrm{H}_{2} / \mathrm{N}_{2}$ mixture. Their phase structure is remarkably different. Moreover, the structure of the Ni-Mo oxide precursors directly influences the structure of the Ni-Mo nitrides. The Ni-Mo nitride catalysts exhibit different reactivity and mobility of the $\mathrm{N}$ species in them, which results in the different catalytic properties in propane ammoxidation. The Ni-Mo nitride-CP shows the highest catalytic activity and selectivity for ACN. The redox properties of the Ni-Mo nitride catalysts are helpful to determine the catalytic activity for propane ammoxidation. This reaction mechanism over $\mathrm{Ni}$-Mo nitride catalyst is analogous to the Mars-van Krevelen one. The existence of a passivation layer is crucial, because it offers an active 0 species at the beginning of the reaction. Lattice $\mathrm{N}$ is involved in the propane ammoxidation. The high content, mobility, and reactivity of the $\mathrm{N}$ species in the Ni-Mo nitrides improve the selectivity for ACN.

\section{References}

[1] Korlann S, Diaz B, Bussell M E. Chem Mater, 2002, 14: 4049

[2] Volpe L, Boudart M. J Phy Chem, 1986, 90: 4874

[3] Liang C H, Li W Z, Wei Z B, Xin Q Li C. Ind Eng Chem Res, 2000, 39: 3694

[4] Zheng W Q, Cotter T P, Kaghazchi P, Jacob T, Frank B, Schlichte K, Zhang W, Su D S, Schüth F, Schlögl R. J Am Chem Soc, 2013, 135 : 3458

[5] Andonova S, Vladov C, Kunev B, Mitov I, Tyuliev G, Fierro J L G, Damyanova S, Petrov L. Appl Catal A, 2006, 298: 94

[6] Monnier J, Sulimma H, Dalai A, Caravaggio G. Appl Catal A, 2010, 382: 176

[7] Hunter S M, Mckay D, Smith R I, Hargreaves J S J, Gregory D H. Chem Mater, 2010, 22: 2898

[8] Hunter S M, Gregory D H, Hargreaves J S J, Richard M, Duprez D, Bion N. ACS Catal, 2013, 3: 1719

[9] Ding J H, Xu L, Xu H, Wu H H, Liu Y M, Wu P. Chin J Catal (丁姜宏, 徐乐, 徐浩, 吴海虹, 刘月明, 吴鹏. 催化学报), 2013, 34: 243

[10] Jiang F, Deng S C, Niu L, Xiao G M. Chin J Catal (姜枫, 邓生财, 牛否, 肖国民. 催化学报), 2013, 34: 1833

[11] Li X K, Ji W J, Zhao J, Zhang Z B, Au C T. Appl Catal A, 2006, 306: 8

[12] Wickman A, Andersson A. Appl Catal A, 2011, 391: 110

[13] Pyrz W D, Blom D A, Vogt T, Buttrey D J. Angew Chem Int Ed, 2008, 47: 2788

[14] Shiju N R, Guliants V V. Catal Commun, 2008, 9: 2253

[15] Safonova O V, Florea M, Bilde J, Delichere P, Millet J M M. J Catal, 2009, 268: 156

[16] Sadakane M, Kodato K, Kuranishi T, Nodasaka Y, Sugawara K, Sakaguchi N, Nagai T, Matsui Y, Ueda W. Angew Chem Int Ed, 2008, 47: 2493

[17] Zhang H M, Zhao Z, Xu C M, Duan A J. Chem Lett, 2006, 35: 36

[18] Derouane-Abd Hamid S B, Pal P, He H Y, Derouane E G. Catal Today, 2001, 64: 129

[19] Centi G, Perathoner S, Trifirò F. Appl Catal A, 1997, 157: 143

[20] Olea M, Florea M, Sack I, Silvy R P, Gaigneaux E M, Marin G B, Grange P. J Catal, 2005, 232: 152

[21] Jacobsen C J H, Zhu J J, Lindelöv H, Jiang J Z. J Mater Chem, 2002, 


\title{
Graphical Abstract
}

Chin. J. Catal., 2014, 35: 286-293 doi: 10.1016/S1872-2067(14)60015-2

Ni-Mo nitride catalysts: Synthesis and application in the ammoxidation of propane

Xiaoqiang Fan, Huimin Zhang, Jianmei Li, Zhen Zhao*, Chunming Xu, Jian Liu*, Aijun Duan, Guiyuan Jiang, Yuechang Wei

China University of Petroleum; Shenhua Group Corporation Ltd

Precursor preparation methods affect the structure and properties of nitrides. Lattice nitrogen species participate in propane ammoxidation reaction. The mechanism for propane ammoxidation over the Ni-Mo nitride is analogous to the Mars-van Krevelen mechanism.

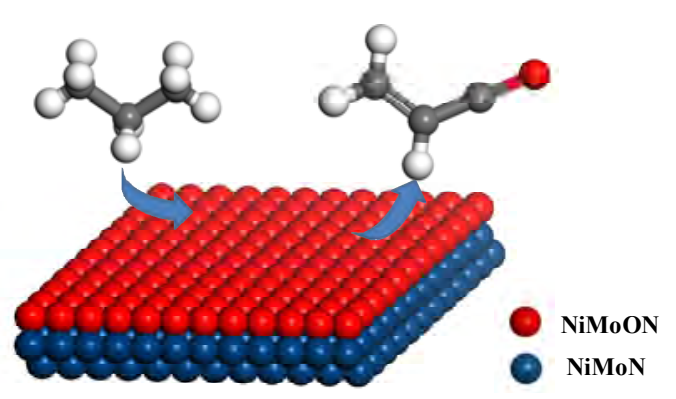

12: 3113

[22] Weil K S, Kumta P N, Grins J. J Solid State Chem, 1999, 146: 22

[23] Wang H M, Li W, Zhang M H. Chem Mater, 2005, 17: 3262

[24] Markel E J, Van Zee J W. J Catal, 1990, 126: 643

[25] Choi J G, Curl R L, Thompson L T. J Catal, 1994, 146: 218

[26] Wise R S, Markel E J. J Catal, 1994, 145: 344

[27] Guyader J, Grekov F F, Marchand R, Lang J. Rev Chim Miner, 1978, 15: 431

[28] Herle P S, Hegde M S, Sooryanarayana K, Row T N G, Subbanna G N. Inorg Chem, 1998, 37: 4128

[29] Zhang H M, Zhao Z. Ind Catal (张惠民, 赵震. 工业催化), 2008, 16(9): 34

[30] Cárdenas-Lizana F, Lamey D, Perret N, Gómez-Quero S, Kiwi-
Minsker L, Keane M A. Catal Commun, 2012, 21: 46

[31] Wang Y H, Li W, Zhang M H, Guan N J, Tao K Y. Appl Catal A, 2001, 215: 39

[32] Colling C W, Thompson L T. J Catal, 1994, 146: 193

[33] Levin D, Ying J Y.J Electroceramics, 1999, 3: 25

[34] Zhang Q H, Cao C J, Xu T, Sun M, Zhang J Z, Wang Y, Wan H L. Chem Commun, 2009: 2376

[35] Chen J G.J Catal, 1995, 154: 80

[36] Ghampson I T, Sepúlveda C, Garcia R, Fierro J L G, Escalona N, DeSisto W J. Appl Catal A, 2012, 435-436: 51

[37] Nagai M, Takada J, Omi S. J Phys Chem B, 1999, 103: 10180

[38] Yao Z W, Zhang A J, Li Y, Zhang Y Z, Cheng X Q, Shi C. J Alloy Comp, 2008, 464: 488

\section{Ni-Mo氮化物催化剂: 合成及其丙烷氨氧化催化性能}

\author{
范晓强 ${ }^{\mathrm{a}, \dagger}$, 张惠民 ${ }^{\mathrm{b}, \dagger}$, 李建梅 ${ }^{\mathrm{a}}$, 赵 震 ${ }^{\mathrm{a}}{ }^{*}$, 徐春明 ${ }^{\mathrm{a}}$, 刘 坚 ${ }^{\mathrm{a}, \#}$, 段爱军 ${ }^{\mathrm{a}}$, 姜桂元 ${ }^{\mathrm{a}}$, 韦岳长 ${ }^{\mathrm{a}}$ \\ a中国石油大学(北京)重质油国家重点实验室, 北京102249 \\ $\mathrm{b}^{\mathrm{x}}$ 神华集团有限责任公司煤制油化工部，北京100011
}

摘要: 分别采用溶胶-凝胶法、旋转蒸发微波干燥法、共沉淀法、浸渍法和机械混合法制备 $\mathrm{Ni}-\mathrm{Mo}$ 氧化物前驱体. 以 $\mathrm{H}_{2}$ 和 $\mathrm{N}_{2}$ 的混 合气为氮化气体, 采用程序升温氮化法合成了镍钿氮化物催化剂. 利用 $\mathrm{X}$ 射线衍射、总氮含量分析、 $\mathrm{X}$ 射线光电子能谱及 $\mathrm{H}_{2}$ 程序 升温还原对 $\mathrm{Ni}-\mathrm{Mo}$ 氧化物前体及氮化物催化剂进行了表征. 将上述 Ni-Mo氮化物催化剂用于丙烷氨氧化反应中. 结果表明, $\mathrm{Ni}-\mathrm{Mo}$ 氧化物前驱体的制备方法影响其氮化物催化剂上丙烷氨氧化反应性能. Ni-Mo氮化物催化剂中氮物种的移动性及反应性 对产物丙烯腈选择性的影响较大, 共沉淀法制备的催化剂存在大量的活性氮物种, 因而具有良好的催化丙烷氨氧化反应活性.

关键词: 镍钿氮化物; 丙烷氨氧化; 丙烯腈; 制备方法; 氮物种

收稿日期: 2013-11-03. 接受日期: 2013-12-27. 出版日期: 2014-03-20.

†共同第一作者.

*通讯联系人. 电话: (010)89731586; 传真: (010)69724728; 电子信箱: zhenzhao@cup.edu.cn

\#通讯联系人. 电话: (010)89732326; 传真: (010)69724728; 电子信箱: liujian@cup.edu.cn

基金来源：国家自然科学基金(21073235, 21173270, 21177160); 国家高技术研究发展计划(863计划, 2013AA065302F); 中国石油 大学基金(LLYJ-2011-39 and KYJJ2012-06-31).

本文的英文电子版由Elsevier出版社在ScienceDirect上出版(http://www.sciencedirect.com/science/journal/18722067). 